\title{
Relation of lung function and exercise capacity to mood and attitudes to health
}

\author{
B KING, J E COTES
}

From the University Departments of Occupational Health and Physiological Sciences, Newcastle upon Tyne

ABSTRACT Results of psychometric tests were obtained on 161 male welders and other tradesmen in heavy industry who had recently been made redundant. Anxiety and depression were scored on the Hospital Anxiety and Depression Scale, and negative attitudes and beliefs regarding breathlessness and related aspects of respiratory health on a semantic differential scale. Scores for attitudes and beliefs about health and personal disability were pooled to give a general attitude score. Personality was rated on a standard scale. Subjects completed a questionnaire on respiratory symptoms and underwent routine spirometry, measurement of carbon monoxide transfer factor for the lung, and a progressive exercise test on a cycle ergometer. Scores for anxiety, depression, and negative mental attitudes were significantly intercorrelated; subjects with disordered personality profiles had above average scores for anxiety and depression. The psychometric scores were associated with clinical grade of breathlessness, lung function, and the physiological response to exercise. The general attitude score could be predicted from the anxiety and depression scores and from lung function expressed relative to age and stature, the combination of mood score and $\mathrm{FEV}_{1}$ explaining $38 \%$ of the variance in general attitude score. The general attitude score accounted for more than half the explained variance in the clinical grade of breathlessness and contributed more to the variance in maximal oxygen uptake $\left(R^{2}=0.11\right)$ than $F E V_{1}$. It was associated with the level of habitual activity but not with smoking category, wheeze, chronic cough or phlegm. Thus attitude to disability reflected the subject's assessment of his exercise capacity and was closely related to the clinical grade of breathlessness.

\section{Introduction}

Undue breathlessness on exertion is the principal symptom of most chronic lung diseases in working men and is associated with a reduction in exercise capacity. The symptom develops insidiously and the person often imagines that the cause is merely increasing age. Medical help is usually sought only after more than $30 \%$ of the previous capacity has been lost. By this stage the changes in exercise capacity may be irreversible and this may cause the man to take a gloomy view of his respiratory and general health. These negative attitudes were shown by Morgan and colleagues to be a better guide to loss of exercise capacity than the forced expiratory volume in one second $($ FEV $)$, forced vital capacity (FVC), or trans-

Address for reprint requests: Dr J E Cotes, Respiration and Exercise Laboratory, Department of Occupational Health, Medical School, Newcastle upon Tyne NE2 4HH.

Accepted 21 February 1989 fer factor for carbon monoxide (TLCo).' Subsequent work suggested that the lung function indices were a less good guide to exercise capacity than the physiological response to submaximal exercise. ${ }^{2}$ Nevertheless, psychological tests were better predictors of exercise capacity than physiological indices even if submaximal exercise tests were taken into account. ${ }^{3}$ We need to determine therefore, with a view to prevention and rehabilitation, whether negative attitudes to health occur among working men and what is their association with lung function, respiratory symptoms, and exercise capacity. Accordingly we have studied men from heavy industry who had recently been made redundant, knowing that the prevalence of minor respiratory impairment among such men is relatively high. ${ }^{4}$

\section{Methods}

SUBJECTS

The subjects were 161 welders and other tradesmen in 
heavy industry who had recently been made redundant. The assessments were carried out in conjunction with a respiratory survey and were approved by the local ethical committee. The men were seen initially at their homes, where the Medical Research Council questionnaire on respiratory symptoms $(1976)^{*}$ was completed and an occupational history obtained. Habitual physical activity was rated on a four point scale going from (1) inactive, (2) occasional exercise, (3) regular but non-competitive sport, and (4) participation in competitive sport. ${ }^{5}$ Subjects then attended the laboratory for measurement of ventilatory capacity by dynamic spirometry, carbon monoxide transfer factor of the lung by the single breath method, and the physiological response to progressive submaximal exercise on a cycle ergometer. A self administered questionnaire scoring anxiety and depression and a semantic differential assessing the subjects's attitudes and beliefs regarding his health were completed.

\section{LUNG FUNCTION TESTING}

Spirometry was performed with a dry bellows spirometer ${ }^{6}$ with digital display of forced expiratory volume $\left(\mathrm{FEV}_{1}\right)$, forced vital capacity (FVC), peak expiratory flow (PEF), and the flow rates when $50 \%$ and $25 \%$ of vital capacity remained to be expired $\left(\mathrm{MEF}_{50}\right.$ and $\left.\mathrm{MEF}_{25}\right)$. Before use a volume calibration was carried out with a gas syringe and the timing was checked by using a weight and standard orifice. Three technically satisfactory results were obtained and the highest value for each index was included in the analysis.

Total lung capacity and its subdivisions (residual volume, expiratory reserve volume, and inspiratory capacity) were measured by closed circuit spirometry with helium as the indicator gas. For measurement of TLCO a gas mixture comprising $0.3 \%$ carbon monoxide and $14 \%$ helium in air and a transfer test apparatus (Morgan) was used, the gas analysers being calibrated by standard methods. ${ }^{7}$ The breath holding time included two thirds of the inspiratory time, the time of deadspace washout and half the time of sample collection. Alveolar volume was volume inspired plus residual volume measured by closed circuit spirometry; it was used to obtain transfer coefficient (KCO) - that is, TLCo divided by alveolar volume. Stature was measured with a stadiometer (Harpenden) during vertical traction to the head. Fat free mass (FFM) was obtained from body mass, measured with a calibrated spring balance, together with an estimate of the percentage of body fat. The percentage of fat was obtained by the method of Durnin and Womer-

*Obtainable from the Medical Research Council, 20 Park Cresent, London WIN 4AL. sley ${ }^{8}$; this and the other methods are described in detail elsewhere. ${ }^{9}$

\section{BICYCLE ERGOMETRY}

One hundred and twenty nine of the 161 subjects exercised on a bicycle ergometer (subjects with abnormalities on a 12 lead electrocardiogram suggesting ischaemia and also men with arthritis and others for whom exercise might be inappropriate were assessed only at rest); pedal frequency was $50-60 / \mathrm{min}$ and the load was increased each minute. The endpoint was when the subject chose to stop, the cardiac frequency rose to $80 \%$ of the predicted maximum, the electrocardiogram recorded from the chest leads in the CM5 configuration showed evidence of ischaemia, or the respiratory exchange ratio reached unity $(R=1 \cdot 0)$. Ventilation was measured with a vane anemometer and the concentrations of oxygen and carbon dioxide in mixed expired gas were measured with physical gas analysers (Morgan). These items of equipment were calibrated twice daily. The results were used to obtain the minute by minute relation of ventilation to consumption of oxygen and hence, by interpolation, the ventilation at an oxygen consumption of $45 \mathrm{mmol}$ $\min ^{-1}\left(\dot{\mathrm{V}}_{45}\right)$. The corresponding index of cardiac frequency $\left(\mathrm{fC}_{45}\right)$ was obtained concurrently. The plot of ventilation against tidal volume was used to obtain the tidal volume at a minute ventilation of $301 \mathrm{~min}^{-1}$ $\left(\mathrm{VT}_{30}\right)$. For subjects who discontinued exercise because of breathlessness or other symptom the maximal oxygen uptake was that for the last or penultimate half minute of exercise, whichever was the higher. For subjects who discontinued because the respiratory exchange ratio reached unity the maximal oxygen uptake was estimated by using a prediction equation derived from the results for similar subjects ${ }^{\text {s: }}$

$$
\begin{gathered}
\text { no }_{2} \max =0.626 .\left(\dot{\mathrm{nO}}_{2} \text { at } \mathrm{R}_{\mathrm{1} .0}\right)+0.78 \mathrm{FFM}-0.86 \% \\
\text { fat }-0.29 \mathrm{fC}_{45}+70.1 \text { (SD 12.1) } \mathrm{mmol} \mathrm{min}^{-1} \text {. }
\end{gathered}
$$

Reference values were taken from the same source and used to express the maximal oxygen uptake ( ( $_{2}$ max) as a percentage of the predicted maximum $\left(\right.$ ṅ $\left._{2} \max (\%)\right)$ :

$$
\begin{aligned}
& \dot{\text { nO}}_{2} \mathrm{max} \%=100 \times \text { no }_{2} \mathrm{max} \text { observed or } \\
& \text { calculated } / \text { no }_{2} \mathrm{max}_{\text {predicted. }}
\end{aligned}
$$

Immediately after exercise the subject was engaged in conversation to provide an external estimate of breathlessness and to determine the symptoms or other reason for terminating the exercise and the level of perceived exertion (Borg). The exercise procedure is detailed elsewhere. ${ }^{10}$

\section{PSYCHOLOGICAL QUESTIONNAIRES}

The psychological questionnaires were administered by one observer (BK). Anxiety and depression were assessed on the 21 point hospital anxiety and depres- 
sion scale. " Each subject was screened for personality disorder according to a personality assessment schedule. ${ }^{12}$ This led to classification of subjects as having either a normal or a disordered personality. Personality disorders were classified on the basis of 13 separate diagnoses, which were in four groups: antisocial, dependent, inhibited, and withdrawn. These broad diagnoses were used in the analysis.

The subject's attitudes and beliefs regarding health were measured by using a semantic differential ${ }^{13}$ modified from that used by Morgan and collegues.' The attitudes studied were to "my general health," "myself," "my breathlessness," "my breathlessness can be improved," "physical exercise," and "physical exercise is good for me"; they were tested by using pairs of contrasting adjectives (concepts, table 1). Each pair of contrasting adjectives was linked by a line subdivided to give a seven point scale going from positive (optimistic) to negative (pessimistic) or vice versa. The scale was marked by the subject at the point that best indicated his feelings. Before analysis the scales were rearranged with the positive (optimistic) pole scored as 1 and the negative pole as 7 .

\section{ANALYSIS}

For each subject the semantic differential yielded 44 scores divided between six attitudes. As many of the scores and attitudes were intercorrelated the scores for each individual were reduced to two composite ones for the purpose of analysis. This was done by principal component analysis, which redistributed the scores into a series of factors, of which the first contained the bulk of the information. Initially each attitude was analysed separately; the concepts that contributed to the first factor were identified and the sum of their scores formed the score for the attitude (table 2); the scores for the other concepts were omitted (table 1). The scores for all the attitudes were then analysed in the same way. The first factor contained material contributions from five of the attitude scores: these were summed without weighting to yield a general
Table 1 Concepts used in the semantic differential (for scoring see text)

\begin{tabular}{|c|c|}
\hline $\begin{array}{l}\text { MY GENERAL HEALTH } \\
\text { Awful/nice } \\
\text { Sick/healthy } \\
\text { Pleasurable/painful } \\
\text { Pleasant/unpleasant } \\
\text { Bad/good } \\
\text { Weak/strong } \\
\text { Well/unwell }\end{array}$ & $\begin{array}{l}\text { MYSELF } \\
\text { Healthy/sick } \\
\text { Awful/nice } \\
\text { Pleasant/unpleasant } \\
\text { Unsociable/sociable } \\
\text { Bad/good } \\
\text { Rugged/delicate* } \\
\text { Independent/dependent* } \\
\text { Slow/fast } \\
\text { Unemotional/emotional* } \\
\text { Strong/weak } \\
\text { Sad/happy } \\
\text { Relaxed/tense }\end{array}$ \\
\hline $\begin{array}{l}\text { MY BREATHLESSNESS } \\
\text { Sick/healthy } \\
\text { Nice/awful } \\
\text { Is never a nuisance/is always a } \\
\text { nuisance }\end{array}$ & $\begin{array}{l}\text { MY BREATHLESSNESS CAN BE } \\
\text { IMPROVED } \\
\text { Impossible/possible } \\
\text { Probable/improbable } \\
\text { False/true }\end{array}$ \\
\hline $\begin{array}{l}\text { Pleasurable/painful } \\
\text { Does not make me feel bitter/ } \\
\text { makes me feel bitter }\end{array}$ & Likely/unlikely \\
\hline $\begin{array}{l}\text { Causes financial worries/does } \\
\text { not cause financial worries } \\
\text { Bad/good } \\
\text { Unpleasant/pleasant }\end{array}$ & \\
\hline
\end{tabular}

PHYSICAL EXERCISE IS GOOD FOR ME PHYSICAL EXERCISE Slow/fast

Valuable/worthless

Pleasant/unpleasant

Safe/dangerous

Bad/good

Awful/nice

Important/unimportant

Hard/easy

Probable/improbable

Impossible/possible

Unlikely/likely

True/false

*Not included in the final scores.

attitude score. The sixth attitude, "my breathlessness can be improved," was correlated only weakly with the others (table 3), and was treated as a separate variable in the analysis. The scores for anxiety and depression were treated both as continuous variables (scored 0 21) and as dichotomous variables (present or absent), scores of 7 or above being taken as indicating that the feature was present. The results obtained by the two methods of scoring were very similar; those for the

Table 2 Distribution of psychological scores

\begin{tabular}{|c|c|c|c|c|}
\hline & Mean & Median & Range & No of concepts* \\
\hline $\begin{array}{l}\text { Hospital anxiety and depression scale } \\
\text { Anxiety } \\
\text { Depression } \\
\text { Semantic differential } \\
\text { Attitude to: }\end{array}$ & $\begin{array}{l}4 \cdot 29 \\
5 \cdot 15\end{array}$ & $\begin{array}{l}4.0 \\
5.0\end{array}$ & $\begin{array}{l}0-18 \\
0-18\end{array}$ & - \\
\hline $\begin{array}{l}1 \text { my general health } \\
2 \text { myself } \\
3 \text { my breathlessness } \\
4 \text { my breathlessness can be improved } \\
5 \text { physical exercise } \\
6 \text { physical exercise is good for me } \\
\text { General attitude score }(\Sigma 1,2,3,5,6)\end{array}$ & $\begin{array}{r}19 \cdot 3 \\
21 \cdot 7 \\
28 \cdot 8 \\
10 \cdot 3 \\
14 \cdot 1 \\
8 \cdot 2 \\
92 \cdot 1\end{array}$ & $\begin{array}{r}18 \cdot 0 \\
21 \cdot 0 \\
27 \cdot 0 \\
9 \cdot 5 \\
12 \cdot 0 \\
7 \cdot 0 \\
89 \cdot 0\end{array}$ & $\begin{array}{l}7-45 \\
9-43 \\
9-62 \\
4-28 \\
7-42 \\
4-28 \\
35-197\end{array}$ & $\begin{array}{r}7 \\
9 \\
9 \\
4 \\
7 \\
4 \\
36\end{array}$ \\
\hline
\end{tabular}

*See table 1 for the individual concepts. 
Table 3 Simple cross correlations between the psychological scores*

\begin{tabular}{|c|c|c|c|c|c|c|c|c|c|}
\hline & & \multicolumn{8}{|c|}{ Psychological score } \\
\hline & & $l$ & 2 & 3 & 4 & 5 & 6 & 7 & 8 \\
\hline $\begin{array}{l}1 \\
2 \\
3 \\
4 \\
5 \\
6 \\
7 \\
8 \\
9\end{array}$ & $\begin{array}{l}\text { Anxiety } \\
\text { Depression } \\
\text { General attitude } \\
\text { My general health } \\
\text { Myself } \\
\text { My breathlessness can be improved } \\
\text { My breathlessness } \\
\text { Physical exercise } \\
\text { Physical exercise is good for me }\end{array}$ & $\begin{array}{l}- \\
0.74 \\
0.56 \\
0.57 \\
0.63 \\
0.14 \\
0.33 \\
0.36 \\
0.37\end{array}$ & $\begin{array}{l}0.58 \\
0.58 \\
0.61 \\
\text { NS } \\
0.42 \\
0.36 \\
0.31\end{array}$ & $\begin{array}{l}0 \cdot 88 \\
0 \cdot 81 \\
0 \cdot 33 \\
0 \cdot 83 \\
0 \cdot 79 \\
0 \cdot 72\end{array}$ & $\begin{array}{l}0.78 \\
0.28 \\
0.70 \\
0.55 \\
0.52\end{array}$ & $\begin{array}{l}0.26 \\
0.51 \\
0.52 \\
0.53\end{array}$ & $\begin{array}{l}0.23 \\
0.40 \\
0.35\end{array}$ & $\begin{array}{l}0.52 \\
0.46\end{array}$ & 0.81 \\
\hline
\end{tabular}

*The scores were independent of age, stature, fat free mass, and smoking category.

continuous variables are reported. The scores for anxiety and depression were correlated with most of the individual attitude scores (table 3) and also with the general attitude score; to avoid error due to collinearity in multiple regression analysis, not more than one psychological index was included at a time in the main analysis.

The variables that best described the respiratory symptoms, lung function, and the physiological response to exercise were identified by multiple regression and logistic regression analysis. The independent variables were the psychological indices and the reference variables-age, stature, smoking history, trade, fat free mass/stature ${ }^{2}$ and percentage of fat. Exsmokers were defined as men who had discontinued smoking for a minimum of one month; those who had done so within the last 10 years were "recent exsmokers." The reference variables were not significantly correlated with each other or with the psychological variables, so could be entered concurrently into the multiple regression analysis. The psychological indices were entered singly after the contribution of the reference variables had been established; they were entered both in linear form and after logarithmic transformation, which had the effect of improving the symmetry of their distribution. The two methods produced similar results; the linear results are reported. For the analysis of lung function the measurements for all 161 subjects were used. Confining it to the 129 men who performed the exercise test led to a nearly identical result.

An IBM 370 computer was used with the SPSS ${ }^{x}$ package of Statistical Programmes for the Social Sciences of the University of Michigan. ${ }^{14}$ The BMDP package ${ }^{15}$ was used for the logistic regression analysis. The $5 \%$ level of probability was accepted as significant.

\section{Results}

During the study 299 men were visited at home, of whom 169 subsequently attended the laboratory and 161 took part in the study. Of the remainder, 55 were ill or refused to attend and 75 failed to keep appointments for the psychological tests and in eight cases the information was not complete. The subjects comprised 101 welders, 36 caulkers or burners, and 24 other tradesmen. They were mainly in the later part of their working life and their lung function ranged from normal to greatly impaired (table 4). The principal abnormality was airflow obstruction but a few men had restriction of lung expansion or defective gas transfer or both. The psychological scores for anxiety and depression similarly covered a wide range but with a distribution skewed towards the lower or more normal end of the scales. When scores based on dichotomous variables were used, 31 men were defined as anxious and 40 as depressed. The personality assessment suggested that 20 subjects had disordered personalities; seven were classed as antisocial, one as dependent, three as inhibited and nine as withdrawn personalities. Personality defined in this way did not correlate with lung function or attitude scores. Subjects identified as having disordered personalities did, however, have above average scores for anxiety and depression. For the semantic differential a variable number of concepts contributed to the several attitude scores (table 1), which therefore differed in magnitude (table 2); for each attitude the average score per concept was in the range $2-3$.

The general attitude score could be predicted from the score for anxiety or depression and the result of the relatively effort independent lung function tests$\mathrm{FEV}_{1}, \mathrm{MEF}_{50}$ or $\mathrm{MEF}_{25}$-standardised for age and stature. The combination of either of the mood scores and $F E V_{1}$ explained $38 \%$ of the variance in the general attitude score $\left(R^{2}=0.38\right)$; rather less was accounted for when the other lung function indices were used. When the mood was depression the prediction was increased by a further $2 \%$ by the addition of the index of exercise ventilation $\left(\dot{\mathrm{V}}_{45}\right)$.

The contributions of the psychological scores to the 
Table 4 Mean values and ranges for the physiological indices and related variables (for lung function $n=161$, for exercise $n=129$ )

\begin{tabular}{|c|c|c|c|c|}
\hline & & Mean & Range & Reference value \\
\hline $\begin{array}{l}\text { Age } \\
\text { Stature } \\
\text { Fat free mass } \\
\text { Forced expiratory volume } \\
\text { Forced vital capacity } \\
\text { FEV } / \text { FVC } \\
\text { Peak expiratory flow } \\
\text { Maximal expiratory flow rate at } 50 \% \text { FVC } \\
\text { Maximal expiratory flow rate at } 25 \% \text { FVC } \\
\text { Transfer factor } \\
\text { Transfer coefficient } \\
\text { Maximal oxygen uptake } \\
\text { Ventilation at no }=45 \mathrm{mmol} \mathrm{min}_{2}^{-1} \\
\text { Cardiac frequency at no } \mathrm{m}_{2}=45 \mathrm{mmol} \mathrm{min}^{-1} \\
\text { Tidal volume at ventilation of } 301 \mathrm{~min}^{-1}\end{array}$ & 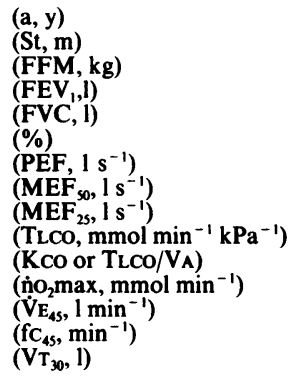 & $\begin{array}{l}55 \cdot 6 \\
1 \cdot 706 \\
56 \cdot 1 \\
2 \cdot 69 \\
4 \cdot 09 \\
65 \cdot 0 \\
7 \cdot 0 \\
2 \cdot 8 \\
0 \cdot 8 \\
9 \cdot 76 \\
1 \cdot 54 \\
89 \cdot 3 \\
26 \cdot 7 \\
102 \\
1 \cdot 78\end{array}$ & $\begin{array}{l}27-71 \\
1 \cdot 5-1 \cdot 8 \\
39-90 \\
0 \cdot 4-4 \cdot 8 \\
1 \cdot 3-6 \cdot 9 \\
25-87 \\
1 \cdot 2-12 \\
0 \cdot 3-7 \cdot 5 \\
0 \cdot 1-3 \cdot 0 \\
2 \cdot 8-14 \cdot 8 \\
0 \cdot 5-2 \cdot 6 \\
16-127 \\
19-50 \\
60-154 \\
0 \cdot 9-3 \cdot 2\end{array}$ & $\begin{array}{c}3.0 \\
4.1 \\
71.0 \\
8.9 \\
\\
\\
8.98 \\
1.48 \\
101 \\
24 \\
1.4\end{array}$ \\
\hline
\end{tabular}

*For age $56 \mathrm{y}$, stature $1.7 \mathrm{~m} .^{9}$

total explained variance for each of the physiological indices are shown in table 5. For FEV, $29 \%$ of the variance was accounted for by the reference variables age, stature, smoking history, fat free mass, and percentage of body fat. Including the anxiety score increased the explained variance to $33.1 \%$ (that is, $29.0+4 \cdot 1)$, including the depression score increased it to $32 \cdot 1 \%$, and including the general attitude score increased it to $39 \cdot 2 \%$. Individually, all the attitude scores except "my breathlessness can be improved" contributed significantly to the description of $\mathrm{FEV}_{1}$. For FVC the anxiety and general attitude scores also contributed significant information, whereas the depression score did not. The results for $\mathrm{FEV}_{1} / \mathrm{FVC}$

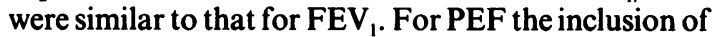
the general attitude score more than doubled the explained variance, with more modest contributions from the anxiety or depression scores. All three scores contributed to the description of $\mathrm{MEF}_{5_{0}}$ but none to the description of $\mathrm{MEF}_{25}$, though there was an association with the attitude to "my breathlessness."

The psychological scores did not make a material contribution to the predictions of indices of gas transfer. Depression did not contribute to the description of the exercise indices. Anxiety made a significant contribution to maximal oxygen uptake as percentage of predicted $\left(\mathrm{no}_{2} \max (\%)\right)$ but not to the indices obtained during submaximal exercise. By contrast, the general attitude score contributed to all the exercise indices with the exception of submaximal exercise cardiac frequency $\left(\mathrm{fC}_{45}\right)$. The $\mathrm{fC}_{45}$ was, however, described in part by the scores for attitudes to general health and the benefits of physical exercise (table 5).

The no $\mathrm{O}_{2} \max (\%)$ showed a significant negative correlation with the anxiety score and general attitude score but was independent of the score for depression.

Table 5 Variance in physiological indices associated with the reference variables and the additional variance accounted for by each of the psychological scores (\%)

\begin{tabular}{|c|c|c|c|c|c|}
\hline & $\begin{array}{l}\text { Reference } \\
\text { variables* }\end{array}$ & Anxiety & Depression & $\begin{array}{l}\text { General } \\
\text { attitude score }\end{array}$ & $\begin{array}{l}\text { Attitudes } \\
\text { contributing } \dagger\end{array}$ \\
\hline 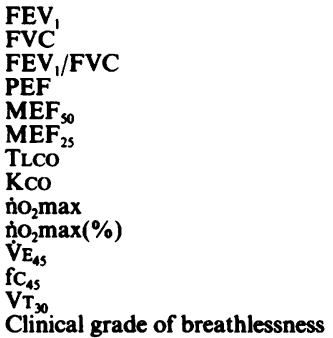 & $\begin{array}{l}29 \cdot 0 \\
33 \cdot 7 \\
13 \cdot 0 \\
14 \cdot 8 \\
16 \cdot 3 \\
25 \cdot 9 \\
27 \cdot 4 \\
8 \cdot 1 \\
13 \cdot 0 \\
= \\
21 \cdot 1 \\
4 \cdot 8 \\
20 \cdot 4\end{array}$ & $\begin{array}{l}4 \cdot 1 \\
1 \cdot 6 \\
5 \cdot 2 \\
4 \cdot 7 \\
2 \cdot 4 \\
\text { NS } \\
1 \cdot 8 \\
\text { NS } \\
\text { NS } \\
4 \cdot 2 \\
\text { NS } \\
\text { NS } \\
\text { NS } \\
2 \cdot 1\end{array}$ & $\begin{array}{l}3 \cdot 1 \\
\text { NS } \\
6 \cdot 4 \\
4 \cdot 0 \\
4 \cdot 5 \\
\text { NS } \\
\text { NS } \\
\text { NS } \\
\text { NS } \\
\text { NS } \\
\text { NS } \\
\text { NS } \\
\text { NS } \\
2 \cdot 0\end{array}$ & $\begin{array}{c}10 \cdot 2 \\
5 \cdot 4 \\
9 \cdot 6 \\
18 \cdot 8 \\
4 \cdot 3 \\
\text { NS } \\
\text { NS } \\
\text { NS } \\
11 \cdot 0 \\
8 \cdot 6 \\
14 \cdot 5 \\
\text { NS } \\
7 \cdot 9 \\
24 \cdot 8\end{array}$ & $\begin{array}{l}1,2,3,5,6 \\
1,2,3,5,6 \\
1,2,3,6 \\
1,2,3,5,6 \\
1,2,3,6 \\
3 \\
3 \\
3 \\
1,2,3,4,5,6 \\
1,2,3,4,5,6 \\
1,2,3,5,6 \\
1,6 \\
1,2,5,6 \\
1,3,5,6\end{array}$ \\
\hline
\end{tabular}

*Age, stature, smoking, fat free mass, and percentage of fat.

†1-my general health; 2-myself; 3-my breathlessness; 4 -my breathlessness can be improved; 5-physical exercise; 6-physical exercise is 8 good for me.

For abbreviations see table 4 . 
Table 6 Mean lung function values and psychological scores (see text) corresponding to different levels of exercise performance

\begin{tabular}{|c|c|c|c|c|c|c|}
\hline $\begin{array}{l}\text { Maximal oxygen } \\
\text { uptake (\% pred) }\end{array}$ & $\begin{array}{l}F E V_{1} \\
(l)\end{array}$ & $\begin{array}{l}F V C \\
(l)\end{array}$ & $\begin{array}{l}T L C O \\
\left(\mathrm{mmol} \min ^{-1} \mathrm{kPa}^{-1}\right)\end{array}$ & $\begin{array}{l}\text { Anxiety } \\
\text { score }\end{array}$ & $\begin{array}{l}\text { Depression } \\
\text { score }\end{array}$ & $\begin{array}{l}\text { General attitude } \\
\text { score }\end{array}$ \\
\hline $\begin{array}{c}<40 \% \\
40-59 \% \\
60-79 \% \\
80-99 \% \\
\geqslant 100 \% \\
\text { In summary. }\end{array}$ & $\begin{array}{l}2 \cdot 38 \\
2 \cdot 25 \\
2 \cdot 72 \\
2 \cdot 96 \\
2 \cdot 66\end{array}$ & $\begin{array}{l}3 \cdot 63 \\
3 \cdot 74 \\
4 \cdot 02 \\
4 \cdot 26 \\
4 \cdot 14\end{array}$ & $\begin{array}{r}10 \cdot 30 \\
8 \cdot 83 \\
10 \cdot 65 \\
9.96 \\
9 \cdot 54\end{array}$ & $\begin{array}{l}5 \cdot 75 \\
4 \cdot 50 \\
4 \cdot 20 \\
4 \cdot 20 \\
3 \cdot 18\end{array}$ & $\begin{array}{l}5 \cdot 00 \\
5 \cdot 42 \\
4 \cdot 53 \\
4 \cdot 78 \\
4 \cdot 94\end{array}$ & $\begin{array}{r}121 \cdot 2 \\
103 \cdot 9 \\
90 \cdot 5 \\
84 \cdot 8 \\
77 \cdot 1\end{array}$ \\
\hline $\begin{array}{l}<80 \% \\
\geqslant 80 \%\end{array}$ & $\begin{array}{r}2.49 \\
2.83 \\
<0.05\end{array}$ & $\begin{array}{l}3.93 \\
4 \cdot 20 \\
\text { NS }\end{array}$ & $\begin{array}{l}9 \cdot 80 \\
9 \cdot 79 \\
\text { NS }\end{array}$ & $\begin{array}{r}5.60 \\
3.79 \\
<0.01\end{array}$ & $\begin{array}{l}5 \cdot 79 \\
4 \cdot 84 \\
\text { NS }\end{array}$ & $\begin{array}{c}107 \cdot 2 \\
81 \cdot 7 \\
0.001\end{array}$ \\
\hline
\end{tabular}

It was correlated positively with $\mathrm{FEV}_{1}$ but was independent of FVC and TLCO (table 6). When nO $_{2} \max (\%)$ was described in terms of the general attitude score $\left(R^{2}=0.09\right)$, adding $F E V_{1}$, either as the absolute value or as a percentage of the predicted value, did not further increase the explained variance.

Undue breathlessness on exertion was associated with a low $F E V_{1}$ and with wheeze and there were weak associations with anxiety and depression; the general attitude score was a better guide to breathlessness than any of these indices, describing $24.8 \%$ of the explained variance. The psychological indices did not relate to wheeze or chronic bronchitis.

The psychological indices were correlated negatively with the score for habitual activity but were independent of age, percentage of body fat, and smoking category (non-smoker, smoker, or exsmoker). Smoking was associated with wheeze and a relatively low FEV 1 and was independent of the psychological scores. The ex-smokers on average had somewhat higher values for $F E V_{1}$ than the smokers $(p=0.056)$. The trade of welder and caulker/burner was associated with a higher general attitude score than other trades (mean general attitude scores $\mathbf{9 4 . 3}$ and 76.2 units). Trade was not associated with any other indices.

\section{Discussion}

This study examined the relation of psychological state to respiratory symptoms, lung function, and the capacity for exercise in men recently made redundant. The hospital anxiety and depression scale was used both quantitatively and qualitatively, and with a cut off score of 7 it was suggestive but not diagnostic of an abnormal mood, either anxiety or depression. Making the division at a higher score did not materially alter the results, neither did using the scores as continuous variables with or without logarithmic transformation.

Mood contributed to the description of many lung function indices and the grade of breathlessness. Anxiety was also associated with a reduced exercise capacity relative to expected maximal oxygen uptake $\left(\dot{n}_{2} \max (\%)\right)$; it was not, however, associated with an increase in cardiac frequency during submaximal exercise. This might have occurred if anxiety was influencing the exercise performance. Combining the mood and attitude indices into a single composite index did not explain more of the variance in the physiological indices than did the general attitude score alone. These observations suggest that the association of lung function with mood was secondary to an association with attitude to health and not causal. A stronger relation to mood would be expected in more disabled subjects since hypoxaemia predisposes to psychological disturbances ${ }^{16}$ but the mood would still have been a consequence of the impaired lung function and not a cause.

Five attitudes out of the six that were examined contributed to the general attitude score. The attitudes were represented on an additive basis with equal weight given to each; the results were similar whether equal weight was given to each attitude or the five attitudes were scored individually, showing that the results from the general attitude score were stable and not dependent on a particular method of scoring.

The attitude score for "my breathlessness can be improved" did not conform to the same pattern as the others and did not contribute to the description of clinical grade of breathlessness or other dependent variables. This appeared to be because some men who said they were not breathless answered in a negative manner, presumably taking the view that if they did not experience breathlessness they could not experience less. Hence the scores had a bimodal distribution with respect to grade of breathlessness and could not be interpreted on this account.

The general attitude score was associated most strongly with the clinical grade of breathlessness, an index of performance with a large subjective component. It also showed important associations with peak expiratory flow rate and no $_{2}$ max, both of which are effort dependent, and with the $F E V_{1}$ and $\dot{V E}_{45}$, which in patients with lung disease are predictors of exercise capacity. ${ }^{17}$ The general attitude score was therefore related to the patient's assessment of his exercise 


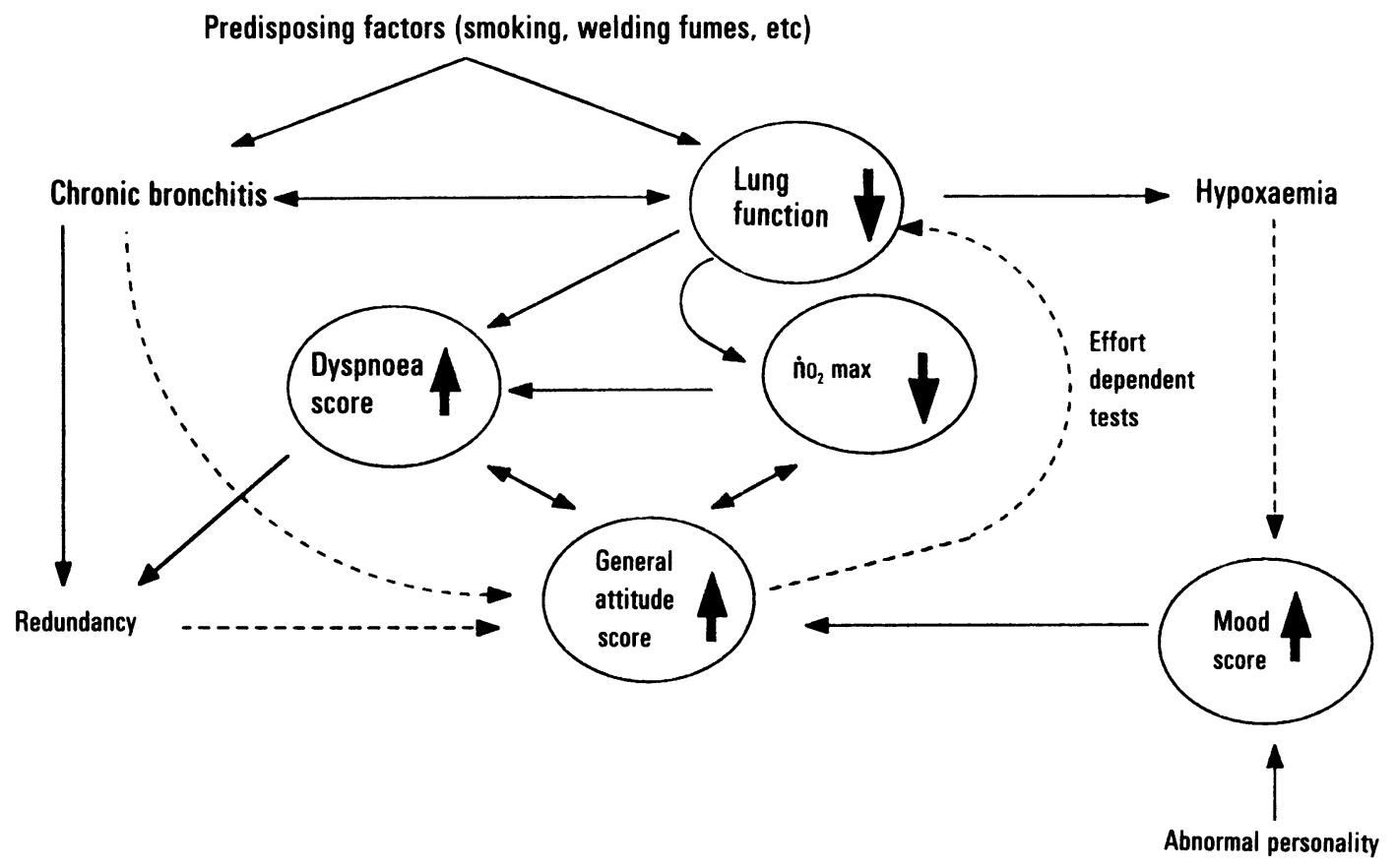

Hypothetical flow diagram with continuing solid arrows indicating relationships suggested by this or the previous study ${ }^{4}$ other likely relationships are indicated by interrupted arrows. Solid arrows indicate changes in the relevant indices. $\mathrm{n}_{2}$ max maximal oxygen uptake.

capacity and to the physiological dimensions that supported it. The associations were somewhat stronger for indices that were effort dependent than for those where effort did not affect performance. This sequence suggested that the general attitude score was conditioned by the exercise capacity, and by environmental and other factors, including mood, that affected the attitude of the patient to his disability. Having an abnormal personality contributed through its influence on mood, though not directly (fig).

The wide range of attitudes observed among men having the same respiratory impairment reflected the many factors that contributed. The present study identified trade as one such factor, welders and burners having a higher general attitude score than other tradesmen. Other factors could have related to personal or family difficulties, including redundancy. Any short term fluctuations in these factors would have contributed to variability in the cross sectional results. In the longer term, trends that persisted could confer stability; thus changes in general attitude scores over time might be expected to be more closely related to respiratory variables than general attitude scores analysed cross sectionally (this was the case for the grade of breathlessness in a previous study ${ }^{18}$ ).

In the present study the grade of breathlessness and the general attitude score were nearly interchangeable, each accounting for almost the same proportions of variance in the physiological indices. The general attitude score could reflect a response to disability; the attitudes could also be formative, by influencing habitual activity. Negative attitudes encourage inactivity, causing unfitness, and an exercise test may thus be discontinued at a lower rate of work than would otherwise have been the case. Positive attitudes would have the opposite effect, and might explain why the exercise capacity of men with respiratory impairment can be improved by exercise training, without any commensurate improvement in lung function. ${ }^{19}$ The association could also explain why, for a given physiological impairment, men who are at work have a higher exercise capacity than those of similar age who are unemployed. ${ }^{2}$ Unexpectedly, attitudes were not different between current smokers and ex-smokers despite the better lung function in the ex-smokers. The act of stopping smoking might have been expected to engender a positive attitude to respiratory health, but many of the present ex-smokers had been persuaded to give up because they were found to have symptoms during the previous survey and this could have affected their attitude.

In this study the men with respiratory impairment 
and associated breathlessness on exertion had negative attitudes to health, as did those with a low level of habitual activity. These features were almost certainly causally related. A possible association with employment could not be investigated in depth as the study was confined to men recently made redundant, and the general attitude score was not related to duration of redundancy. In view of the association between exercise capacity and employment, the general attitude score might be expected to improve in men who return to work. Longitudinal studies should be informative, and might be used to promote the respiratory health and long term employment prospects of men with respiratory impairment. Meanwhile, the general attitude score provides a quantitative index of respiratory well being and is likely to have many applications on this account.

We are indebted to Dr S P Tyrer for advice on psychiatric questionnaires, Dr D J Chinn and $\mathrm{Mr} C$ Elliott for the assessments of lung function, $\mathrm{Dr} \mathrm{V}$ Woolley for statistical advice, Mrs M E Hyam and Mrs J Renwick for secretarial help, and Dr N P Keaney and the Sunderland District Health Authority for the provision of facilities at Ryhope Hospital, where Mrs A Stewart took part in some of the measurements. The study was supported by the European Coal and Steel Community, the Medical Research Council, and the University of Newcastle upon Tyne.

\section{References}

1 Morgan AD, Peck DF, Buchanan DR, McHardy GJR. Effects of attitudes and beliefs on exercise tolerance in chronic bronchitis. Br Med J 1983;286:171-3.

2 Cotes JE, Posner V, Reed JW. Estimation of maximal exercise ventilation and oxygen uptake in patients with chronic lung disease. Bull Eur Physiopathol Respir 1982;18(suppl 4):221-8.

3 Sprake CM, Cotes JE, Reed JW. Correlates of $6 \mathrm{~min}$ walking distance and maximal oxygen uptake in chronic lung disease. Clin Sci 1984;66:57P.

4 Chinn DJ, Stevenson IC, Cotes JE. Longitudinal respiratory survey of shipyard workers: effects of trade and atopic status. Br J Ind Med (in press).

5 Weller JJ, El-Gamal FM, Parker L, Reed JW, Cotes JE. Indirect estimation of maximal oxygen uptake for study of working populations. $\mathrm{Br} J$ Ind Med 1988;45:532-7.

6 McDermott M, McDermott TJ. Digital incremental techniques applied to spirometry. Proc $R$ Soc Med 1977;70:169-71.

7 Chinn DJ, Naruse Y, Cotes JE. Accuracy of gas analysis in lung function laboratories. Thorax 1986;41:133-7.

8 Durnin JVGA, Womersley J. Body fat assessed from total body density and its estimation from skinfold thickness: measurements on 481 men and women aged from 16 to 72 years. Br J Nutr 1974;;32:77-97.

9 Cotes JE. Lung function: assessment and application in medicine. 4th ed. Oxford: Blackwell, 1979.

10 Cotes JE, Steel J. Work-related lung disorders. Oxford: Blackwell, 1987.

11 Zigmond AS, Snaith RP. The hospital anxiety and depression scale. Acta Psychiatr Scand 1983;67:361-70.

12 Tyrer P, Alexander MS, Cicchetti D, Cohen MS, Remington M. Reliability of a schedule for rating personality disorders. Br J Psychol 1979;135:168-74.

13 Osgood CE, Suci GJ, Tannenbaum PH. The measurement of meaning. Urbana, Illinois: University of Illinois Press, 1957.

14 Nie NH, Hull CH, Jenkins JC, Steinbrenner K. Bent DH. Statistical package for the social sciences. 2nd ed. New York: McGraw-Hill, 1975.

15 Dixon WJ (chief editor). BMDP statistical software. Los Angeles: University of California Press, 1981.

16 Crofton J, Douglas A. Respiratory diseases. 3rd ed. Oxford: Blackwell, 1981.

17 Cotes JE, Zejda J, King B. Lung function impairment as guide to exercise limitation in work-related lung disorders. Am Rev Respir Dis 1988;137:1089-93.

18 Musk AW, Cotes JE, Bevan C, Campbell MJ. Relationship between type of simple coalworkers' pneumoconiosis and lung function. A nine-year follow-up study of subjects with small rounded opacities. Br J Ind Med 1981;38:313-20.

19 Cockcroft AE, Saunders MJ, Berry G. Randomisec controlled trial of rehabilitation in chronic respiratory disability. Thorax 1981;36:200-3. 